\title{
Fontes e Níveis de Proteína Bruta em Dietas para Alevinos de Pacu (Piaractus mesopotamicus) ${ }^{1}$
}

\author{
João Batista Kochenborger Fernandes ${ }^{2}$, Dalton José Carneiro ${ }^{3}$, Nilva Kazue Sakomura ${ }^{4}$
}

\begin{abstract}
RESUMO - Foi conduzido um experimento, com 100 dias duração, utilizando-se 288 alevinos de pacu, distribuídos em 36 caixas de cimento amianto com volume de 100 litros, para avaliar a substituição da farinha de peixe por farelo de soja e os níveis protéicos nas dietas. Durante o período experimental, a temperatura média da água permaneceu em $28^{\circ} \mathrm{C}$ e os demais parâmetros limnológicos (oxigênio dissolvido, pH, alcalinidade e condutividade) apresentaram-se dentro dos níveis adequados para o desenvolvimento desta espécie. O delineamento experimental foi de blocos casualizados, em que foram avaliados nove tratamentos em esquema fatorial 3 x 3, três níveis de proteína bruta (22, 26 e 30\%) e três níveis de substituição da farinha de peixe pelo farelo de soja (0,50 e 100\%). O nível de $26 \%$ de proteína bruta foi mais adequado. A farinha de peixe pode ser substituída parcial ou totalmente pelo farelo de soja, sem influir no ganho de peso, na conversão alimentar, na taxa de crescimento específico e na taxa de eficiência protéica dos alevinos. A substituição das fontes protéicas também não influenciou a composição corporal dos peixes, a eficiência de retenção de nitrogênio, o nitrogênio corporal, a gordura corporal e o nitrogênio e a gordura no ganho de peso.
\end{abstract}

Palavras-chave: alevinos de pacu, fontes de proteína, níveis de proteína

\section{Sources and Levels of Crude Protein in Diets for Pacu (Piaractus mesopotamicus) Fingerlings}

\begin{abstract}
A 100-d experiment was carried out with 288 fingerlings of pacu, allotted to 36 cement mansory box with 100 liters volume, with eight fishes per each unit, to evaluate the replacement of fish flour by soybean meal and the protein levels in the diets. During the experimental period, the average temperature of the water was $28^{\circ} \mathrm{C}$ and other limnology parameters (dissolved oxygen, $\mathrm{pH}$, alkalinity and conductivity) remained within the adequate levels for the development of this specie. The experimental design consisted of randomized blocks, with nine treatments in a $3 \times 3$ factorial arrangement, three level of crude protein $(22,26$ and $30 \%)$ and three levels of fish meal replacement by soybean meal $(0,50$ and $100 \%$ ). The results showed that $26 \%$ of crude protein was better and the fish meal, can be partially or totally replaced by soybean meal without affecting fingerlings weight gain, feed: gain, specific growth rate and protein efficiency rate of the fingerlings. The protein source replacement also did not affect the body composition, nitrogen retention efficiency, body nitrogen, body fat and nitrogen and fat in the weight gain of the fingerlings.
\end{abstract}

Key Words: fingerlings of pacu, protein sources, protein levels

\section{Introdução}

No Brasil, nos últimos dez anos, o nível de procura pela criação de peixes em cativeiro tem sido crescente, principalmente pelas espécies nativas tropicais, como o pacu (Piaractus mesopotamicus) e o tambaqui (Colossoma macropomun), que apresentam grande potencial para a piscicultura intensiva, uma vez que possuem carne de excelente qualidade, facilidade de adaptação ao cultivo em tanques ou viveiros e grande utilidade na pesca esportiva.

A farinha de peixe, devido a seu elevado valor nutritivo e palatatibilidade, tem sido tradicionalmente utilizada nas rações comerciais para peixes. Contudo, devido ao alto custo das fontes protéicas, associado à poluição ambiental em função do uso excessivo das fontes nitrogenadas nas dietas, há a necessidade de reavaliação tanto das fontes como dos níveis de proteína a serem utilizadas em formulações comerciais (SILVA e ANDERSON, 1995). Dessa forma, são necessários mais estudos sobre as exigências e fontes protéicas na alimentação do pacu, visando otimizar o seu desempenho. Assim, o objetivo deste estudo foi avaliar a substituição da farinha de peixe por farelo de soja e os níveis protéicos em dietas para alevinos desta espécie.

\footnotetext{
1 Parte da tese de Doutorado em Aqüicultura do primeiro autor apresentada ao Centro de Aqüicultura da UNESP.

2 Zootecnista, técnico especializado em piscicultura do Centro de Aqüicultura da UNESP, Rod. Carlos Tonani, Km 5, 14870-000, Jaboticabal, SP E.mail: jbatista@caunesp.unesp.br

3 Zootecnista, professor do Centro de Aqüicultura da UNESP, Rod. Carlos Tonani, Km5, 14870-000, Jaboticabal, SP.E.mail:daltonjc@caunesp.unesp.br

${ }^{4}$ Zootecnista, professor do Departamento de Zootecnia da FCAV-UNESP, Rod. Carlos Tonani, Km 5, 14870-000, Jaboticabal, SP E.mail: sakomura@fcav.unesp.br
} 


\section{Material e Métodos}

O experimento foi conduzido no Laboratório de Nutrição de Organismos Aquáticos, do Centro de Aqüicultura da UNESP, Campus de Jaboticabal-SP, por um período de 100 dias. Foram utilizados 288 alevinos de pacu, distribuídos em 36 caixas de cimento amianto, com capacidade volumétrica de 100 litros, na proporção de 8 peixes/caixa. Foi realizado o monitoramento da qualidade da água dos aquários experimentais por intermédio de análises físicas e químicas, com leituras de temperatura diária, e semanalmente foram determinados o potencial hidrogeniônico $(\mathrm{pH})$, a alcalinidade total $(\mathrm{mg}$ de $\left.\mathrm{CaCO}_{3} / \mathrm{l}\right)$, a condutividade elétrica ( $\mu$ Siemens/cm) e o oxigênio dissolvido $\left(\mathrm{mg} \mathrm{O}_{2} / \mathrm{l}\right)$, de acordo com o recomendado por POMEROY e KIRSCHIMAN (1945) e GOLTERMAN et al. (1978).

O delineamento experimental foi o de blocos casualizados, com quatro blocos, para controlar as diferenças dos pesos iniciais que estavam entre 4,62 e 11,31 g. Cada repetição foi constituída por oito alevinos. Foram testados nove tratamentos em esquema fatorial $3 \times 3$, três níveis de proteína bruta (22, 26 e $30 \%$ ) e três níveis de substituição da farinha de peixe pelo farelo de soja $(0,50$ e $100 \%)$. De acordo com as análises prévias da composição química dos ingredientes (Tabela 1), foram formuladas nove dietas isocalóricas (4200 kcal EB/kg) com três níveis de

proteína bruta e três níveis de substituição da farinha de peixe por farelo de soja, conforme a composição das rações apresentada na Tabela 2.

Para avaliar a eficiência das dietas experimentais, foram determinados alguns parâmetros de desempenho dos peixes, como consumo, ganho de peso, taxa de crescimento específico, conversão alimentar e taxa de eficiência protéica. Também foram avaliadas a composição corporal dos alevinos (água, nitrogênio e gordura), assim como a taxa de eficiência de retenção de nitrogênio e a porcentagem de nitrogênio e gordura no ganho de peso.

As análises estatísticas foram realizadas utilizando-se o programa ESTAT, desenvolvido na FCAV/ UNESP-Jaboticabal, segundo o modelo matemático:

em que

$$
Y_{i j k}=B_{i}+F_{j}+P_{k}+F \cdot P_{j k}+E_{i j k}
$$

$\mathrm{Y}_{\mathrm{ijk}}=$ variável estudada referente ao bloco $\mathrm{i}$, à fonte $\mathrm{j}$, ao nível $\mathrm{k}$ e à interação $\mathrm{F} \times \mathrm{P}$;

$\mathrm{B}_{\mathrm{i}} \quad=$ efeito do bloco $\mathrm{i}=1,2,3,4$;

$\mathrm{F}_{\mathrm{j}} \quad$ = efeito da fonte de proteína, $\mathrm{j}=1,2,3$;

$\mathrm{P}_{\mathrm{k}} \quad=$ efeito do nível de proteína, $\mathrm{k}=1,2,3$;

F.P $\mathrm{p}_{\mathrm{jk}}=$ efeito do nível da interação da fonte $\mathrm{j} \mathrm{e}$ nível k; e

$\mathrm{E}_{\mathrm{ijk}}=$ erro aleatório associado à observação do i-ésimo bloco, j-ésimo fonte de proteína e k-ésimo nível de proteína, $\mathrm{i}=1-4, \mathrm{j}=1-3$ e $\mathrm{k}=1-3$.

As médias das variáveis estudadas foram comparadas pelo teste de Tukey a $5 \%$.

Tabela 1 - Composição química dos ingredientes utilizados nas rações experimentais Table 1 - Chemical composition of ingredients used in the experimental diets

\begin{tabular}{|c|c|c|c|c|c|c|c|c|}
\hline \multirow[t]{2}{*}{$\begin{array}{l}\text { Composição química } \\
\text { Chemical composition }\end{array}$} & \multicolumn{8}{|c|}{$\begin{array}{l}\text { Ingrediente } \\
\text { Ingredient }\end{array}$} \\
\hline & $\begin{array}{l}\text { Far. peixe } \\
\text { Fish meal }\end{array}$ & $\begin{array}{c}\text { Far. soja } \\
\text { Soybean } \\
\text { meal }\end{array}$ & $\begin{array}{l}\text { Far. arroz } \\
\text { Rice bran }\end{array}$ & $\begin{array}{l}\text { Far. trigo } \\
\text { Wheat meal }\end{array}$ & $\begin{array}{l}\text { Milho } \\
\text { Corn }\end{array}$ & $\begin{array}{c}\text { Óleo } \\
\text { de soja } \\
\text { Soybean } \\
\text { oil }\end{array}$ & $\begin{array}{c}\text { Fosfato } \\
\text { bicálcico } \\
\text { Dicalcium } \\
\text { phosphate }\end{array}$ & $\begin{array}{l}\text { Sal } \\
\text { Salt }\end{array}$ \\
\hline $\begin{array}{l}\text { Matéria seca (\%) } \\
\text { Dry matter }\end{array}$ & 91,45 & 87,22 & 86,94 & 85,71 & 87,21 & - & - & - \\
\hline $\begin{array}{l}\text { Proteína bruta }(\%) \\
\text { Crude protein }\end{array}$ & 55,21 & 47,29 & 13,16 & 16,19 & 8,81 & - & - & - \\
\hline $\begin{array}{l}\text { Energia bruta }(\mathrm{kcal} / \mathrm{kg}) \\
\text { Gross energy }\end{array}$ & 4012 & 4303 & 4638 & 4165 & 3930 & 9100 & - & - \\
\hline $\begin{array}{l}\text { Extrato etéreo }(\%) \\
\text { Ether extract }\end{array}$ & 7,77 & 2,39 & 15,17 & 3,57 & 4,47 & 100 & - & - \\
\hline $\begin{array}{l}\text { Extrato não-nitrogenado (\%) } \\
\text { Nitrogen free extract }\end{array}$ & 2,74 & 26,1 & 38,08 & 54,31 & 71,18 & - & - & - \\
\hline $\begin{array}{l}\text { Matéria mineral }(\%) \\
\text { Ashes }\end{array}$ & 25,73 & 6,32 & 10,22 & 4,35 & 1,26 & - & - & - \\
\hline $\mathrm{Ca}(\%)$ & 6,10 & 0,36 & 0,11 & 0,12 & 0,02 & - & 23,30 & - \\
\hline $\mathrm{P}(\%)$ & 3,00 & 0,55 & 1,59 & 0,87 & 0,27 & - & 18,50 & - \\
\hline $\mathrm{Cl}(\%)$ & 0,99 & 0,04 & 0,08 & 0,04 & 0,05 & - & - & 60,66 \\
\hline $\mathrm{Na}(\%)$ & 0,30 & 0,09 & 0,04 & 0,04 & 0,02 & - & - & 39,34 \\
\hline
\end{tabular}


Tabela 2 - Composição percentual e calculada das dietas experimentais Table 2 - Percentage and calculated composition of experimental the diets

\begin{tabular}{|c|c|c|c|c|c|c|c|c|c|}
\hline $\begin{array}{l}\text { Ingrediente } \\
\text { Ingredient } \\
\end{array}$ & $\begin{array}{c}\mathrm{FP}^{3} \\
22 \\
\end{array}$ & $\begin{array}{l}\mathrm{FP} \\
26 \\
\end{array}$ & $\begin{array}{l}\mathrm{FP} \\
30 \\
\end{array}$ & $\begin{array}{c}\mathrm{FP} / \mathrm{FS}^{4} \\
22 \\
\end{array}$ & $\begin{array}{c}\mathrm{FP} / \mathrm{FS} \\
26 \\
\end{array}$ & $\begin{array}{c}\mathrm{FP} / \mathrm{FS} \\
30 \\
\end{array}$ & $\begin{array}{c}\mathrm{FS}^{5} \\
22 \\
\end{array}$ & $\begin{array}{l}\text { FS } \\
26\end{array}$ & $\begin{array}{r}\mathrm{FS} \\
30 \\
\end{array}$ \\
\hline $\begin{array}{l}\text { Farinha de peixe } \\
\text { Fish meal }\end{array}$ & 22,00 & 33,11 & 42,73 & 13,25 & 17,65 & 22,45 & - & - & - \\
\hline Farelo de soja & - & - & - & 14,90 & 20,70 & 26,12 & 29,43 & 41,60 & 52,71 \\
\hline $\begin{array}{l}\text { Soybean meal } \\
\text { Farelo de arroz } \\
\text { Rice bran }\end{array}$ & 29,40 & 28,40 & 19,63 & 18,14 & 10,05 & 5,42 & 15,00 & 10,00 & 10,00 \\
\hline $\begin{array}{l}\text { Farelo de trigo } \\
\text { Wheat meal }\end{array}$ & 24,30 & 10,00 & 10,00 & 10,40 & 12,00 & 10,20 & 20,00 & 14,46 & 10,00 \\
\hline $\begin{array}{l}\text { Milho } \\
\text { Corn }\end{array}$ & 22,80 & 26,64 & 24,85 & 40,21 & 36,00 & 32,47 & 32,30 & 30,00 & 24,04 \\
\hline $\begin{array}{l}\text { Óleo de soja } \\
\text { Soybean oil }\end{array}$ & 0,50 & 1,00 & 2,00 & 2,00 & 2,50 & 2,63 & 1,49 & 1,81 & 1,17 \\
\hline $\begin{array}{l}\text { Fosfato bicálcico } \\
\text { Dicalcium phosphate }\end{array}$ & - & - & - & - & - & - & 0,75 & 1,11 & 1,08 \\
\hline $\begin{array}{l}\text { Sal } \\
\text { Salt }\end{array}$ & 0,30 & 0,15 & 0,09 & 0,40 & 0,40 & 0,01 & 0,33 & 0,32 & 0,30 \\
\hline $\begin{array}{l}\text { Sup. vitamínico }{ }^{1} \\
\text { Vitamin premix }\end{array}$ & 0,45 & 0,45 & 0,45 & 0,45 & 0,45 & 0,45 & 0,45 & 0,45 & 0,45 \\
\hline $\begin{array}{l}\text { Sup. mineral } \\
\text { Mineral premix }\end{array}$ & 0,25 & 0,25 & 0,25 & 0,25 & 0,25 & 0,25 & 0,25 & 0,25 & 0,25 \\
\hline
\end{tabular}

Composição calculada/Analisada

Calculated composition/Analyzed

\begin{tabular}{|c|c|c|c|c|c|c|c|c|c|}
\hline $\begin{array}{l}\text { Matéria seca } \\
\text { Dry matter }\end{array}$ & 91,69 & 91,72 & 92,64 & 92,11 & 92,04 & 92,53 & 90,94 & 92,84 & 91,51 \\
\hline Proteína bruta & 21,97 & 26,00 & 30,00 & 22,00 & 26,00 & 30,00 & 22,00 & 26,00 & 30,00 \\
\hline $\begin{array}{l}\text { Crude protein } \\
\text { Extrato etéreo }\end{array}$ & 8,61 & 9,49 & 9,81 & 8,34 & 7,95 & 7,14 & 6,66 & 6,20 & 5,40 \\
\hline $\begin{array}{l}\text { Ether extract } \\
\text { Extrato não-nitrogenado } \\
\text { Nitrogen free extract }\end{array}$ & 41,22 & 36,11 & 31,77 & 45,43 & 41,85 & 38,15 & 47,25 & 43,87 & 40,11 \\
\hline $\begin{array}{l}\mathrm{Ca} \\
\mathrm{P} \\
\text { Fibra bruta }\end{array}$ & $\begin{array}{l}1,41 \\
1,40 \\
4,68\end{array}$ & $\begin{array}{l}2,07 \\
1,60 \\
3,64\end{array}$ & $\begin{array}{l}2,64 \\
1,75 \\
2,89\end{array}$ & $\begin{array}{l}0,90 \\
0,97 \\
3,70\end{array}$ & $\begin{array}{l}1,18 \\
1,00 \\
3,37\end{array}$ & $\begin{array}{l}1,49 \\
1,08 \\
3,09\end{array}$ & $\begin{array}{l}0,33 \\
0,80 \\
4,73\end{array}$ & $\begin{array}{l}0,44 \\
0,80 \\
4,48\end{array}$ & $\begin{array}{l}0,47 \\
0,80 \\
4,64\end{array}$ \\
\hline $\begin{array}{l}\text { Crude fiber } \\
\text { En. bruta }(\mathrm{kcal} / \mathrm{kg})\end{array}$ & 4200 & 4200 & 4200 & 4200 & 4207 & 4216 & 4200 & 4200 & 4200 \\
\hline $\begin{array}{l}\text { Gross energy } \\
\text { Metionina } \\
\text { Methionine }\end{array}$ & 0,54 & 0,70 & 0,84 & 0,46 & 0,55 & 0,64 & 0,33 & 0,38 & 0,43 \\
\hline $\begin{array}{l}\text { Metionina+Cistina } \\
\text { Methionine }+ \text { Cystine }\end{array}$ & 0,85 & 1,03 & 1,20 & 0,78 & 0,91 & 1,05 & 0,69 & 0,79 & 0,89 \\
\hline $\begin{array}{l}\text { Lisina } \\
\text { Lysine }\end{array}$ & 1,40 & 1,84 & 2,24 & 1,31 & 1,64 & 1,97 & 1.13 & 1,41 & 1,69 \\
\hline $\begin{array}{l}\text { Treonina } \\
\text { Threonine }\end{array}$ & 0,88 & 1,09 & 1,27 & 0,87 & 1,03 & 1,20 & 0,81 & 0,97 & 1,12 \\
\hline $\begin{array}{l}\text { Triptofano } \\
\text { Tryptophan } \\
\end{array}$ & 0,28 & 0,32 & 0,37 & 0,28 & 0,34 & 0,36 & 0,30 & 0,35 & 0,41 \\
\hline $\begin{array}{l}1 \text { Suplemento vitamínico (Vitar } \\
\left.\text { (vit. } \mathrm{B}_{1}\right), 2 \text { mg; riboflavina (rib } \\
0,5 \mathrm{mg} \text {; ácido pantotêmico ( } \\
2 \text { Suplemento mineral (Mineral } \\
3 \text { Farinha de peixes (Fish meal) } \\
4 \text { Farinha de peixe + Farelo de } \\
5 \text { Farelo de soja (Soybean meal) }\end{array}$ & $\begin{array}{l}\text { prem } \\
\text { (avin) } \\
\text { thote } \\
\text { nix): } \mathrm{F}\end{array}$ & $\begin{array}{l}12.0 \\
8 \mathrm{mg} \\
15 \mathrm{~m} \\
; \mathrm{Cu},\end{array}$ & $\begin{array}{l}\text { vit. } D_{3} \\
\text { xina }(p \\
\text { ina }(n \\
\text { Mn, } 70\end{array}$ & $\begin{array}{l}0 \mathrm{UI} \\
\text { in) (vi } \\
40 \mathrm{~m} \\
\mathrm{Co}, 0\end{array}$ & $\begin{array}{l}0 \mathrm{UI} \\
\mathrm{mg} ; \mathrm{b} \\
\text { ina (c } \\
\text { ? mg; }\end{array}$ & $\begin{array}{l}5 \mathrm{~m} \\
\text { (bioti } \\
350 \\
\mathrm{mg} ;\end{array}$ & $\begin{array}{l}\text { t. } B_{12}, 25 \\
00 \mathrm{mg} ; \mathrm{c} c \\
\\
, 50 \mathrm{mg} .\end{array}$ & $\begin{array}{l}\text { g; tia } \\
\text { o fólic }\end{array}$ & (tiamin) \\
\hline
\end{tabular}




\section{Resultados e Discussão}

\section{Parâmetros limnológicos da água dos aquários experimentais}

Os resultados das análises da água dos aquários experimentais, realizadas durante o período experimental, são apresentados na Tabela 3.

$\mathrm{O}$ teor médio de oxigênio dissolvido, durante o período experimental, foi de $4,84 \mathrm{mg} / \mathrm{L}$. Segundo BOYD (1982), os valores obtidos atenderam perfeitamente as exigências dos peixes. Da mesma forma, o potencial hidrogeniônico $(\mathrm{pH})$ manteve-se dentro dos padrões recomendados pelo mesmo autor e por CASTAGNOLLI e CYRINO (1986), entre 6,80 e 7,60 . Os níveis de alcalinidade total e condutividade elétrica da água ficaram entre 91,66 e 94,00 mg de $\mathrm{CaCO}_{3} / \mathrm{l}$ e 166,66 e 190,00 mS/cm, respectivamente. Os valores de alcalinidade apresentaram-se dentro dos limites preconizados por TAVARES (1995). Contudo, os resultados da condutividade elétrica foram elevados, provavelmente em função da alta presença de íons de cálcio na água de abastecimento dos aquários experimentais. A temperatura da água dos aquários experimentais apresentou-se adequada para os peixes tropicais, apresentando médias entre 27,89 e $28,51^{\circ} \mathrm{C}$. Estes valores foram semelhantes aos obtidos por TORLONI et al. (1984) e CARNEIRO (1990), que observaram os melhores parâmetros de desempenho para alevinos de pacu com temperaturas entre 26,7 e $28,8^{\circ} \mathrm{C}$ e 28 e $32^{\circ} \mathrm{C}$, respectivamente.
Desempenho produtivo dos alevinos

Os resultados de desempenho dos alevinos de pacu são apresentados na Tabela 4. Observa-se que as fontes e os níveis de proteína avaliados não interferiram no consumo de ração $(P>0,05)$. Isto pode ser explicado pelo fato de que as rações eram isoenergéticas, haja vista que o nível energético da dieta pode limitar o consumo dos peixes (CARNEIRO, 1990). Verifica-se que, no decorrer do experimento, houve aumento no consumo, principalmente em função do crescimento dos peixes e da adequada temperatura da água para o desenvolvimento da espécie.

Apesar de não ocorrerem diferenças estatísticas entre as fontes protéicas testadas, os alevinos que receberam a farinha de peixe (FP), como principal fonte protéica, apresentaram tendência de menor ganho de peso, em relação àqueles que receberam farelo de soja (FS), enquanto a mistura farinha de peixe mais farelo de soja (FP+FS) tendeu a apresentar melhores resultados. Isto pode ser explicado pelo fato de a ração FP+FS apresentar melhor balanceamento dos aminoácidos e macrominerais, permitindo melhor atendimento das exigências nutricionais dos peixes. Resultados semelhantes foram obtidos por VIOLA et al. (1982), que, substituindo a farinha de peixe por farelo de soja até o nível de $45 \%$, não encontraram prejuízos no desempenho de carpas (Cyprinus carpio). Posteriormente, VIOLA et al. (1988) obtiveram resultados semelhantes com tilápias híbridas (Oreochromis nilotius $x$ O. aureus).

Tabela 3 - Parâmetros limnológicos da água das caixas de cimento experimentais ${ }^{1}$

Table 3 - Water limnological parameters of experimental cement mansory boxes ${ }^{1}$

\begin{tabular}{|c|c|c|c|c|c|}
\hline & $\begin{array}{l}\text { 1으oríodo } \\
1^{\text {st }} \text { Period }\end{array}$ & $\begin{array}{l}2^{\underline{o}} \text { Período } \\
2^{\text {nd }} \text { Period }\end{array}$ & $\begin{array}{l}3^{\text {o }} \text { Período } \\
3^{\text {rd }} \text { Period }\end{array}$ & $\begin{array}{l}4 \text { o Período } \\
4^{\text {th }} \text { Period }\end{array}$ & $\begin{array}{l}\text { Média } \\
\text { Average }\end{array}$ \\
\hline Oxigênio dissolvido (mg/L) & 6,86 & 4,33 & 4,13 & 4,06 & 4,84 \\
\hline $\begin{array}{l}\text { Dissolved oxigen }(\mathrm{mg} / \mathrm{L}) \\
\mathrm{pH}(\text { potencial hidrogeniônico) } \\
\text { pH (hydrogenic potential) }\end{array}$ & 7,60 & 7,20 & 6,80 & 6,80 & 7,10 \\
\hline $\begin{array}{l}\text { Alcalinidade }\left(\mathrm{mg} / \mathrm{LCaCO}_{3}\right) \\
\text { Alcalinity }\left(\mathrm{mg} / \mathrm{LCaCO}_{3}\right)\end{array}$ & 94,00 & 92,00 & 91,66 & 94,33 & 93,00 \\
\hline $\begin{array}{l}\text { Condutividade }(\mathrm{ms} / \mathrm{cm}) \\
\text { Condutivity }(\mathrm{ms} / \mathrm{cm})\end{array}$ & 190,00 & 190,00 & 180,00 & 166,66 & 181,66 \\
\hline $\begin{array}{l}\text { Temperatura média }\left({ }^{\circ} \mathrm{C}\right) \\
\text { Average temperature }\left({ }^{\circ} \mathrm{C}\right)\end{array}$ & 27,89 & 27,90 & 28,51 & 28,37 & 28,16 \\
\hline
\end{tabular}

(1) Médias obtidas em todos os aquários experimentais por período.

(1) Averages obtaneid in all experimental aquariuns per period. 
Tabela 4 - Valores de F, coeficiente de variação (CV) e médias obtidas no desempenho dos alevinos de pacu

Table 4 - F values, variation coefficients and averages on performance of pacu fingerlings

\begin{tabular}{|c|c|c|c|c|c|}
\hline \multirow{3}{*}{$\begin{array}{l}\text { Estatística } \\
\text { Statistic }\end{array}$} & \multicolumn{5}{|c|}{ Parâmetros (Parameters) } \\
\hline & Consumo & GP & TCE & Peso & $\mathrm{CA}$ \\
\hline & Intake & $W G$ & $S G R$ & Weight & $F C$ \\
\hline $\begin{array}{l}\text { F Bloco } \\
\text { Block F }\end{array}$ & $3,1208^{*}$ & $0,8304^{\mathrm{ns}}$ & $36,0246^{* *}$ & $9,1614^{* *}$ & $1,2651^{\mathrm{ns}}$ \\
\hline Fonte de proteína (FP) & $0,6077^{\mathrm{ns}}$ & $2,6752^{\mathrm{ns}}$ & $2,6533^{\mathrm{ns}}$ & $2,7592^{\mathrm{ns}}$ & $1,9746^{\mathrm{ns}}$ \\
\hline $\begin{array}{l}\text { Nível de proteína (NP) } \\
\text { Protein level }\end{array}$ & $0,3523^{\mathrm{ns}}$ & $12,6049^{* *}$ & $3,9297^{*}$ & $14,8420^{* *}$ & $7,1318^{* *}$ \\
\hline $\begin{array}{l}\text { Interação FP x NP } \\
\text { Interaction } F P \times N P\end{array}$ & $0,5478^{\mathrm{ns}}$ & $0,5013^{\mathrm{ns}}$ & $0,5478^{\mathrm{ns}}$ & $0,7276^{\mathrm{ns}}$ & $1,9601^{\mathrm{ns}}$ \\
\hline $\mathrm{CV}(\%)$ & 12,55 & 11,27 & 8,33 & 8,93 & 12,86 \\
\hline $\begin{array}{l}\text { Fontes } \\
\text { Sources }\end{array}$ & & & $\begin{array}{l}\text { lias } \\
\text { ages }\end{array}$ & & \\
\hline $\begin{array}{l}\text { Farinha de peixe } \\
\text { Fish meal }\end{array}$ & 41,29 & 31,41 & 1,67 & 38,85 & 1,37 \\
\hline $\begin{array}{l}\text { Far. peixe }+ \text { Far. soja } \\
\text { Fish meal }+ \text { soybean meal } \\
\text { Farelo de soja } \\
\text { Soybean meal }\end{array}$ & 45,59 & 34,94 & 1,80 & 42,32 & 1,23 \\
\hline
\end{tabular}

Níveis
Levels

$22 \% \mathrm{~PB}(C P)$

40,79

$29,02^{\mathrm{b}}$

$26 \% \mathrm{~PB}(C P)$

41,93

$33,89^{\mathrm{a}}$

$43,11 \quad 36,57^{\mathrm{a}}$

$43,11 \quad 36,57^{\mathrm{a}}$

$1,64^{\mathrm{b}}$

$1,77^{\mathrm{ab}}$

$36,22^{\mathrm{b}}$

$41,23^{\mathrm{a}}$

$1,44^{\mathrm{a}}$

$30 \% \mathrm{~PB}(C P)$

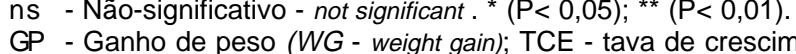

GP - Ganho de peso (WG - weight gain); TCE - tava
CA - Conversão alimentar (FC - feed:gain ratio).

Médias, na coluna, seguidas de letras diferentes são diferentes $(P<0,05)$ pelo teste Tukey.

Means, within a column, followed by different letters are different $(P<.05)$ by Tukey test.

Por outro lado, o nível de $22 \%$ PB proporcionou os piores resultados de ganho de peso. Os níveis de 26 e $30 \%$ PB não apresentaram diferenças significativas, demonstrando que $26 \% \mathrm{~PB}$ podem atender as exigências da espécie nesta fase.

Seguindo a mesma tendência, apesar de não apresentar diferenças significativas, a ração com FP+FS também tendeu a apresentar os melhores resultados para a taxa de crescimento específico (TCE). Contudo, houve diferenças entre os níveis protéicos testados sobre a TCE. O nível de 30\% PB, apesar de ter apresentado os melhores resultados, não diferiu estatisticamente do nível de $26 \% \mathrm{~PB}$. Entretanto, o nível protéico mais baixo apresentou os piores resultados. JAUNCEY (1982), que trabalhou com tilápia nilótica, e BRENNER (1988), com pacu, não encontraram diferenças significativas para a TCE, ao utilizarem dietas com 30; 35; e 40\% PB.

Corroborando os resultados obtidos com o ganho de peso e a taxa de crescimento específico, a curva de crescimento dos alevinos (Figura 1), assim como a conversão alimentar (CA), mostrou que não houve diferenças significativas entre as rações formuladas apenas com FP ou FS. Entretanto, a mistura das fontes $(\mathrm{FP}+\mathrm{FS})$ proporcionou tendência de maior peso final e melhor CA. Também não houve diferenças significativas entre os níveis de 30 e $26 \%$ PB. Contudo, os peixes que receberam $22 \%$ PB apresentaram pior conversão alimentar e menor peso corporal. Segundo COX e COUTANT (1981), a conversão alimentar, o crescimento e as taxas de consumo variam com a temperatura da água. LOVELL (1984) relatou que os peixes, em geral, aproveitam melhor as dietas com teores protéicos mais altos, de maneira similar aos resultados obtidos no presente estudo.

Apesar de não ocorrerem diferenças estatísticas entre as fontes e níveis de proteína sobre a taxa de eficiência protéica (TEP) e a eficiência de retenção de nitrogênio (ERN), observou-se nítida tendência de a dieta composta por FP+FS apresentar os melhores 
FERNANDES et al.

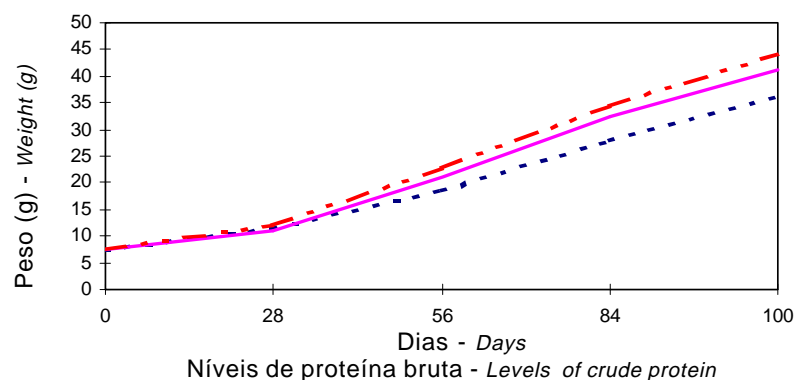

- - - - $22 \%-26 \% \quad--30 \%$

Figura 1 - Curvas de crescimento dos alevinos alimentados com diferentes fontes e níveis de proteína.

Figure 1 - Performance of fingerlings fed different sources and levels of protein. resultados para estes parâmetros (Tabela 5). Estes resultados podem indicar melhor composição da dieta mista no balanço de aminoácidos, resultando em melhor desempenho dos peixes. Respostas semelhantes foram obtidas por VIDOTTI (1997), com alevinos de bagre africano (Clarias gariepinus), em rações compostas por $50 \%$ de farinha de peixe e $50 \%$ de farelo de soja. SHIAU et al. (1989), trabalhando com tilápias híbridas, obtiveram resultados semelhantes ao presente estudo, ou seja, TEP entre 3,7 e 4,6. Quanto aos níveis de proteína bruta testados, observou-se que os peixes que receberam dietas com $22 \%$ PB apresentaram TEP e ERN mais elevadas, o que pode estar associado ao uso mais eficiente da proteína, quando esta se apresenta deficiente na ração.

Tabela 5 - Valores de F, coeficiente de variação (CV) e médias da utilização de proteína e composição corporal dos alevinos de pacu

Table 5 - $\quad F$ values, coefficients of variation and means of protein utilization and body composition of pacu fingerlings

\begin{tabular}{|c|c|c|c|c|c|c|c|}
\hline \multirow{4}{*}{$\begin{array}{l}\text { Estatística } \\
\text { Statistic }\end{array}$} & \multicolumn{7}{|c|}{ Parâmetros } \\
\hline & \multicolumn{7}{|c|}{ Parameters } \\
\hline & TEP & Água & Proteína & Gordura & ERN & NGP & GGP \\
\hline & PER & Water & Protein & Fat & $N E R$ & $W G N$ & $W G F$ \\
\hline F Bloco & 1,0560 & 1,3172 & 1,3963 & 0,1763 & 1,6069 & 1,2756 & 0,7605 \\
\hline \multicolumn{8}{|l|}{ Block F } \\
\hline Fonte de proteína (FP) & 2,7419 & $8,7192^{* *}$ & $14,7089^{* *}$ & $3,4190^{*}$ & 2,8366 & 0,8133 & 2,2533 \\
\hline \multicolumn{8}{|l|}{ Protein source } \\
\hline Nível de proteína (NP) & 2,2575 & $8,3720^{* *}$ & $24,2542^{* *}$ & 0,2039 & 1,2930 & $5,6058^{*}$ & 2,1060 \\
\hline Protein level & & & & & & & \\
\hline Interação FP x NP & 1,8937 & 1,5594 & $4,1384^{*}$ & 1,7121 & 2,1337 & 1,2482 & 1,7138 \\
\hline \multicolumn{8}{|l|}{ Interaction $F P \times N P$} \\
\hline $\mathrm{CV}(\%)$ & 11,47 & 1,04 & 2,67 & 10,72 & 10,42 & 2,80 & 12,16 \\
\hline Fontes & \multicolumn{7}{|c|}{ Médias } \\
\hline Sources & \multicolumn{7}{|c|}{ Averages } \\
\hline Farinha de peixe & 2,94 & $72,41^{\mathrm{a}}$ & 55,58 & 29,53 & 44,85 & 2,43 & 9,21 \\
\hline \multicolumn{8}{|l|}{ Fish meal } \\
\hline Far. Peixe + Far. soja & 3,27 & $71,85^{\mathrm{b}}$ & 54,39 & 26,55 & 49,64 & 2,43 & 8,29 \\
\hline Fish meal + Soybean meal & & & & & & & \\
\hline Farelo de soja & 3,07 & $73,13^{\mathrm{a}}$ & 57,65 & 29,16 & 47,25 & 2,46 & 8,70 \\
\hline \multicolumn{8}{|l|}{ Soybean meal } \\
\hline \multicolumn{8}{|l|}{ Níveis } \\
\hline \multicolumn{8}{|l|}{ Levels } \\
\hline $22 \% \mathrm{~PB}(C P)$ & 3,23 & $71,95^{\mathrm{b}}$ & 53,98 & 28,66 & 48,52 & $2,39^{\mathrm{b}}$ & 9,12 \\
\hline $26 \% \mathrm{~PB}(C P)$ & 3,13 & $72,28^{\mathrm{b}}$ & 55,47 & 28,62 & 47,78 & $2,44^{\mathrm{ab}}$ & 8,84 \\
\hline $30 \% \mathrm{~PB}(C P)$ & 2,92 & $73,16^{\mathrm{a}}$ & 58,16 & 27,95 & 45,43 & $2,49^{\mathrm{a}}$ & 8,25 \\
\hline
\end{tabular}

${ }_{*}^{*}(\mathrm{P}<0,05)^{* *}(\mathrm{P}<0,01)$.

TEP - Taxa de eficiência protéica (PER- protein efficiency rate); ERN - eficiência de retenção de nitrogênio (NRE - nitrogen retention efficiency);

NGP - Nitrogênio no ganho de peso (WGN - protein in weight gain); GGP - gordura no ganho de peso (WGF - weight gain). Médias, na coluna, seguidas de letras diferentes são diferentes $(P<0,05)$ pelo teste Tukey.

Means, within a column, followed by different letters are different $(P<.05)$ by Tukey test. 
652 Rev. bras. zootec.

Por outro lado, em níveis protéicos mais elevados, a proteína da dieta poderá ser parcialmente utilizada como fonte de energia, induzindo os peixes a apresentarem menor valor da TEP e ERN. Resultados semelhantes foram obtidos por BRENNER (1988), com alevinos de pacu, e HERNANDES (1995), com alevinos de tambaqui, em que os melhores resultados da TEP foram alcançados com as rações que continham níveis protéicos mais baixos.

Avaliando-se ainda a composição corporal dos alevinos (Tabela 5), observou-se que as fontes protéicas estudadas interferiram significativamente na retenção de água das carcaças, sendo que a composição FP+FS apresentou o menor índice. Com relação à proteína corporal dos alevinos, foi obtida interação significativa $(\mathrm{P}<0,05)$ entre as fontes e os níveis protéicos testados. Pelo desdobramento da interação, constatou-se que, ao se utilizar FP ou FS, os maiores teores de proteína bruta corporal foram obtidos com o nível mais elevado de proteína na dieta. A mistura FP+FS também proporcionou diferenças significativas entre os níveis protéicos estudados. $\mathrm{Na}$ avaliação da gordura corporal dos alevinos, foi observado efeito significativo dos tratamentos $(\mathrm{P}<0,05)$ apenas para fonte de proteína. Observou-se que a FP proporcionou valores mais elevados que a combinação FP+FS, o que, provavelmente, porque as rações contendo FP, como principal ingrediente protéico, em sua composição, também apresentaram níveis de ex trato etéreo maiores. Com relação aos níveis de proteína testados, observou-se que, nos mais elevados, as retenções de água e proteína foram maiores. Contudo, a gordura corporal apresentou tendência de diminuir, à medida que o nível de PB se elevou na dieta, indicando direcionamento do extrato etéreo da dieta para uso como fonte energética. MAZID et al. (1979) e MURRAY et al. (1985) também observaram que aumentos nos níveis protéicos induziam a redução da gordura corporal, em tilápia mossambica e carpas, respectivamente.

Observa-se, na Tabela 5, que as fontes de proteína testadas não influíram na porcentagem de nitrogênio, no ganho em peso (NGP) e na porcentagem de gordura no ganho de peso (GGP). Por outro lado, os níveis protéicos proporcionaram diferenças significativas $(\mathrm{P}<0,05)$ para NGP, e, à medida que aumentou a proteína das dietas, houve aumento no NGP. Apesar de o nível mais elevado apresentar a maior taxa de NGP, este não diferiu estatisticamente do nível intermediário $(26 \% \mathrm{~PB})$. Estes resultados sugerem que o aumento do nível de PB na dieta acarretou aumento de nitrogênio corporal proporcional ao ganho de peso dos peixes. Entretanto, verifica-se que, à medida que os níveis protéicos são elevados, a GGP tende a declinar. Isto pode também estar relacionado ao fato de a proteína não ter sido utilizada como fonte energética, possivelmente em função de adequado balanceamento das rações, que poderia ter atendido as necessidades energéticas dos alevinos. Constatou-se que as rações com nível mais elevado de gordura (FP) apresentaram valores mais elevados de GGP.

\section{Conclusões}

A farinha de peixe, tradicionalmente utilizada nas dietas de peixes, pode ser substituída parcial ou totalmente pelo farelo de soja, sem influir no desempenho e prejudicar a composição corporal dos alevinos de pacu.

O nível de $26 \%$ de proteína bruta na dieta dos alevinos foi suficiente para atender as exigências e proporcionar bom desempenho, sem comprometer a composição corporal dos peixes.

\section{Referências Bibliográficas}

BOYD, C.E. 1982. Water quality management for pond fish culture, development in aquaculture and fisheries science. New York: Elsevier. v.9. 730p.

BRENNER, M. Determinação da exigência de proteína do pacu, Colossoma mitrei (Berg, 1895). Viçosa, UFV, 1988. 87p. Dissertação (Mestrado em Zootecnia) - Universidade Federal de Viçosa, 1988.

CARNEIRO, D.J. Efeito da temperatura na exigência de proteína e energia em dietas para alevinos de pacu, Piaractus mesopotamicus (HOLMBERG, 1887). São Carlos, SP: UFSCAR, 1990. 55p. Tese (Doutorado em Ecologia) Universidade Federal de São Carlos, 1990.

CASTAGNOLLI, N., CYRINO, J.E.P. 1986. Piscicultura nos Trópicos. São Paulo: Ed. Manole. 152p.

COX, D.K., COUTANT, C.C. 1981. Growth dynamics of juvenile striped bass as functions of temperature and ration. Trans. Amer. Fish. Soc., 110:226-238.

GOLTERMAN, H.L., CLYMO, R.S., OHNSTAD, M.A.M. 1978. Methods for physical and chemical analysis offreswater: London: Blackwel Science Publications, n.8, 213p. IBP Handbook.

HERNANDEZ, M., TAKEUCHI, T., WATANABE, T. 1995. Effect of dietary energy sources on the utilization of protein by Colossoma macropomum fingerlings. Fisheries Science. 61(3):507-511.

JAUNCEY, K. 1982. The effects of varying dietary protein level on the growth, food conversion, protein utilization and body composition of juvenile tilapias (Sarotherodon mossambicus). Aquaculture, 27:43-54.

LOVELL, R.T. 1984. Use of soybean products in diets for aquaculture species. Quartely Publication of the American Soybean Association. p.1-6.

MAZID, M.A ., TANAKA, Y., KATAYAMA, T. et al. 1979. Growth response of Tilapia zilli fingerlings fed isocaloric diets with variable protein levels. Aquaculture., 18:115-122.

MURRAI, T., AKIYAMA, T., TAKEUCHI, T. et al. 1985. 


\section{FERNANDES et al.}

Effects of dietary protein and lipid levels on performance and carcass composition of fingerlings carp. Bull. Jap. Soc. Sci. Fish.. 51(4):307-316.

POMEROY, R., KIRSCHIMAN, H.D. 1945. Determination of dissolved oxigen proposed modification of the Winkler Method. Ind. Eng. Chem., 17:715-716.

SILVA, S.S de., ANDERSON, T.A. 1995. Fish nutrition in aquaculture. 1.ed. London: Chapman Hall. 319p.

SHIAU, S.Y., KWOK, C.C., KWANG, J.Y. et al. 1989. Replacement of fish meal with soybean meal in male tilapia (Oreochromis niloticus $x O$. aureus) fingerling diets at a suboptimal protein level. J. World Aquac. Soc., 20(4):230-235.

TAVARES,L.H.S. 1995. Limnologia aplicada a aqüicultura. Jaboticabal.: FUNEP. 70p.

TORLONI, C.E.C., SILVA FILHO, J.A ., VERANI, J.R., et al. Estudos experimentais sobre o cultivo intensivo do pacu, Colossoma mitrei, no sudeste do Brasil. In: SIMPÓSIO BRASILEIRO DE AQÜICULTURA, 3, 1983, São Carlos. Anais...São Carlos: UFSCar, 1984, p.559.
VIDOTTI, R.M. Desenvolvimento inicial do bagre africano, (SBURCHELL, 1822) com dietas contendo diferentes niveis proteicos e proporções de proteína de origem animal. Jaboticabal, SP: UNESP, 1997. 49p. Dissertação (Mestrado em Zootecnia) - Universidade Estadual Paulista, 1997.

VIOLA, S., MOKADY, S., RAPPAPORT, U. et al. 1982. Partial and complete replacement of fish meal by soybean meal in feeds for intensive culture of carp. Aquaculture, 26:223-232.

VIOLA, S., ARIELI, Y., ZOHAR, G. 1988. Animal protein free feeds for hybrid tilapia (Oreochromis niloticus $x$ O. aureus) in intensive culture. Aquaculture, 75:115-125.

Recebido em: 13/04/99

Aceito em: 29/09/99 